\title{
Application of Whey Permeate Fermented with Kefir Grains for the Shelf-Life Improvement of Food and Feed
}

\author{
Raúl Ricardo Gamba1,2,3, Candela Moure1, Gabriela Diosma², Leda Giannuzzi", \\ Graciela Liliana De Antoni1,2,5, Ángela María León Peláez ${ }^{1}$ \\ ${ }^{1}$ Cátedra de Microbiología, Facultad de Ciencias Exactas, Universidad Nacional de La Plata, La Plata, Argentina \\ ${ }^{2}$ CIDCA (Centro de Investigación y Desarrollo en Criotecnología de los Alimentos), La Plata, Argentina \\ ${ }^{3}$ CONICET (Consejo Nacional de Investigaciones Científicas y Tecnológicas), CCT-La Plata, La Plata, Argentina \\ ${ }^{4}$ Cátedra de Toxicología, Facultad de Ciencias Exactas, Universidad Nacional de La Plata, La Plata, Argentina \\ ${ }^{5} \mathrm{CIC}$-PBA (Comisión de Investigaciones Científicas-Provincia de Buenas Aires), Buenas Aires, Argentina \\ Email: raulgamba@biol.unlp.edu.ar, anleon@biol.unlp.edu.ar
}

Received 12 July 2016; accepted 6 August 2016; published 9 August 2016

Copyright (C) 2016 by authors and Scientific Research Publishing Inc.

This work is licensed under the Creative Commons Attribution International License (CC BY).

http://creativecommons.org/licenses/by/4.0/

c) (7) Open Access

\begin{abstract}
Fungal contamination by Aspergillus parasiticus and A. flavus causes negative effects on the production of food cereals. Kefir is an ancient fermented beverage obtained by the fermentation of different substrates with kefir grains. An important waste produced by the dairy cheese industry is the whey permeate, which nowadays is a strong ambient contaminant. The aim of this work was the standardization of the whey permeate fermenting conditions with kefir grains, the assessment of the antifungal activity of the cell-free-supernatants (CFS) from these fermentations and to compare it with that obtained with CFS of milk fermented with kefir grains. Finally, we studied if the addition of kefir fermented whey permeate to food (bread) and feed (poultry) could produce shelf life improvement. The optimal condition to obtain CFS with fungicidal effect was a fermentation with $10 \% \mathrm{w} / \mathrm{v}$ of kefir grains, at $30^{\circ} \mathrm{C}$, for 24 hours until a pH 3.7. We found that CFS from whey permeate caused fungal inhibition, whereas CFS of kefir grains grown in milk showed lower antifungal activity. Additionally, the addition of kefir-fermented whey permeates in food (bread) and feed (poultry) improved their resistance to fungal contamination. This is the first report about the application of kefir-fermented whey permeate to improve the shelf life, suggesting its potential use as a biopreservative.
\end{abstract}

\section{Keywords}

Aspergillus parasiticus, Whey Permeate, Kefir Supernatants, Bread, Poultry Feed 


\section{Introduction}

Fungal contamination of food by Aspergillus flavus and A. parasiticus causes large food and feed losses especially in tropical areas, where temperature and humidity favor its development [1] [2]. Contamination problems are frequent in food processing plants, where fungal conidia from raw materials are difficult to eradicate from the environment. Even though molds are destroyed during the baking process, contamination arises from mold spores derived from atmosphere and from surfaces during the cooling, finishing or wrapping procedures [3]. High temperature and humidity in the processing environment cause the fungal prevalence and food contamination.

One alternative that has been widely explored is the application of lactic-acid bacteria, which produce organic acids, exhibit antibacterial and antifungal activities [4]-[9].

Kefir is a sour milk slightly carbonated with a low alcohol content that is obtained through the use of kefir grains. These grains are clusters of lactic- and acetic-acid bacteria along with yeasts in a structural matrix of polysaccharides and proteins. The microorganisms present are responsible for the lactic, acetic, and alcoholic fermentation of milk that yields a product with characteristic organoleptic properties [10].

Kefir-fermented milk supernatants at a concentration of $10 \%(\mathrm{v} / \mathrm{v})$ in a broth completely inhibited the fungal growth of A. flavus and Fusarium graminearum [11]. Cell free supernatants obtained from whey permeate fermented with kefir grains inhibited the $A$. parasiticus and $F$. graminearum growth and the aflatoxin $B_{1}$ and zearalenone production [5] [6].

Argentine is the fifth world cheese producer after the European Union, USA, Russia and Brazil. The estimated production is around 580,000 tons for 2016 [12]. Cheese whey produced after cheese manufacture has diverse applications, mainly the obtention of whey proteins for feed additive. However, after producing protein concentrates, cheese whey permeate (WP) remains as a waste. Due to its composition whey permeate is a strong ambient contaminant [13].

The consumers' demand of biopreservatives in foods, instead of chemical preservatives has arisen since the $\mathrm{XX}$ century. The application of microorganisms classified as GRAS (Generally recognized as safe) such as lactic acid bacteria and their metabolites strongly promoted the research in this area [14]. Even though the obtention of these preservatives require further studies in scaling the volume process, the results obtained are very interesting to continue the assessment of natural preservatives offered to a public increasingly interested in natural foods. Kefir fermented products using WP as substrate could give a solution for the ambient contamination and additionally could be used as biopreservative for food and feed with special application against fungal contamination. Although production costs are not analyzed in this work, the decrease of industrial effluents combined with the development of biopreservatives could generate environmental benefits. Besides, the small companies could avoid unnecessary legal disputes for the effluents disposal.

The aim of this work was to study the kinetic parameters and antifungal effect of kefir grains grown in whey permeates and the application of kefir-fermented products on bread and poultry feed in order to improve their shelf-life. Finally, we studied the sensory properties of bread added with kefir-fermented products.

\section{Materials and Methods}

\subsection{Fungal Cultures and Preparation of Conidia Inoculum}

A. flavus AFUNL5 was isolated from cereals at Laboratorio de Micología, Universidad Nacional del Litoral (Argentina). F. graminearum Fg44 strains were provided kindly by Dr. Teresa Alconada of the Centro de Investigacion y Desarrollo en Fermentaciones Industriales (CINDEFI) of the Universidad Nacional de La Plata (Argentina). A. terreus CMUNLP1, A. fumigatus CMUNLP2, Penicillium sumatrense CMUNLP3, P. crustosum CMUNLP4, Trichoderma longibrachiatum CMUNLP5 and Rhizopus microspores var. rhizopodiformis CMUNLP6 were isolated from the commercial poultry feed Nutrisur ${ }^{\circledR}$ BB (Nutrisur, La Plata, Argentina). A. parasiticus CMUNLP7 was isolated from corn (Dra. León at Cathedra of Microbiology-National University of La Plata). A. parasiticus NRRL 2999 was obtained from the Agricultural Research Service Culture Collection (Washington, DC, USA). Fungi were maintained at $4^{\circ} \mathrm{C}$ in soft agar (2 g/L agar in water) until used. The inoculum was prepared by growing the fungi on PDA (Potato Dextrose Agar) slants (Britania, Argentina) for 7 days at $30^{\circ} \mathrm{C}$. After incubation, $10 \mathrm{ml}$ of $0.01 \%$ (w/v) Sodium Lauryl Sulfate (SLS) in $1 \%(\mathrm{w} / \mathrm{w}$ ) sodium chloride solution were added to the tubes and spores were loosened by gently scraping with a spatula, and serial dilutions 
were made. The number of spores, about $5 \times 10^{5} / \mathrm{ml}$ was assessed by means of account in a Neubauer chamber [15] [16].

\subsection{Preparation of Cell-Free Supernatants and Organic Acid Solutions}

The kefir grains used -CIDCA AGK1 were characterized at the Centro de Investigación y Desarrollo en Criotecnología de Alimentos (CIDCA), UNLP [17] [18] and stored in whole milk at $-20^{\circ} \mathrm{C}$. The kefir grains were activated through two consecutive passages of fermentation in commercial ultra-high-temperature-processed (UHT) milk (Sancor, Santa Fe, Argentina). The grains were inoculated into UHT milk or sterile WP at a concentration of $10 \%(\mathrm{w} / \mathrm{v})$ and incubated at $30^{\circ} \mathrm{C}$ for 24 or $48 \mathrm{~h}$. The fermentation products were then separated from the grains by passage of the fermentation mixture through a sieve of $1 \mathrm{~mm}^{2}$ mesh size and the microorganisms present precipitated by centrifuging for $15 \mathrm{~min}$ at 14,000 $\mathrm{g}$ in an Eppendorf 5415D centrifuge (Eppendorf, Hamburg, Germany).

The standardization of the kefir grains CIDCA AGK1 was carried out as follows: Kefir grains CIDCA AGK1 grown in milk were adapted to WP by consecutive passages of fermentation $\left(24 \mathrm{~h}\right.$ at $\left.30^{\circ} \mathrm{C}\right)$ during four weeks (kefir grains WP-4) or twelve weeks (kefir grains WP-12). The fermentation products obtained from these kefir grains were used on different assays (acidification kinetic, biomass production and addition to food and feed).

The resulting kefir-fermented-whey-permeate cell-free supernatants (KFWP CFS) or kefir-fermented-milk cell-free supernatants (KFM CFS) were obtained by filtration through a microcellulose filter of $0.22-\mu \mathrm{m}$ pore size (Sigma-Aldrich, St. Louis, USA) and stored at $-20^{\circ} \mathrm{C}$ until assayed for antifungal activity. The organic acids solutions were prepared with lactic (Carlo Erba 88\%, Milan, Italy) and acetic acid (Merck, 99.5\%, Darmstadt, Germany). These acids were constituted in sterilized WP and mixed in order to obtain different final concentrations. The solutions were stored at $-20^{\circ} \mathrm{C}$.

\subsection{Fungal Inhibition Assays with KFWP CFS and KFM CFS}

The assays were performed on Petri dishes with the basal medium (BM) containing malt extract (1\% w/v) (Biokar, Beauvais, France), yeast extract (2\% w/v) (Biokar, Beauvais, France) and agar ( $2 \% \mathrm{w} / \mathrm{v})$ (Merck, Darmstadt, Germany). The media were autoclaved at $121^{\circ} \mathrm{C}$ for $15 \mathrm{~min}$. The agar medium at $45^{\circ} \mathrm{C}$ was mixed with the KFWP CFS or with lactic and acetic acid mixtures in order to obtain different final concentrations. Twenty milliliters of supplemented medium were plated in Petri dishes ( $80 \mathrm{~mm}$ diameter) and the final $\mathrm{pH}$ of the medium was determined with a Hannah $\mathrm{pH} 211$ Microprocessor $\mathrm{pH}$ meter.

The assays with KFWP CFS in the media included two different controls to investigate the effect of filter-sterilized WP on fungal growth. In the first, the BM was used alone, while in the second the BM was supplemented with $70 \%(\mathrm{v} / \mathrm{v})$ unfermented WP.

Three plates each of controls or with additions of KFWP CFS or organic acids were inoculated with $10 \mu \mathrm{L}$ of the conidia suspensions at $5 \times 10^{5}$ conidia/mL dispensed by micropipetting in the center of the solidified growth medium.

The diameter of the circular inoculums obtained was assumed as the colony initial diameter. Inoculated plates were incubated at $30^{\circ} \mathrm{C}$ inside plastic boxes containing dishes of water to prevent dehydration. Growth was allowed until the maximum $80 \mathrm{~mm}$ diameter, correspondent to the total Petri dish invasion by mycelium; all cultures were kept in the boxes during 30 days in order to determine the total fungal inhibition [19]. Given that filamentous molds grow on solid media forming a circular colony around the initial inoculation zone, colony diameters were measured each daily by placing the Petri dishes on a millimeter scale illuminated from beneath by a light box. Four diameter measures were taken from the center of each colony and the results were calculated from the mean diameter of the replicate colonies [20].

\subsection{Determination of Growth Rate $\left(K_{D}\right)$ and Lag Phase (Lag)}

Growth rate $\mathrm{KD}(\mathrm{mm} / \mathrm{h})$, was calculated from the regression slope of colony diameter versus time during the linear growth phase, using the Sigma Plot 9.0 ${ }^{\mathrm{TM}}$ software. The lag phase (Lag) is the time in hours required for the colony to grow beyond the inoculation zone (typically $5-7 \mathrm{~mm}$ ). This value corresponded to the point on the abscissa where the regression line intersected the horizontal line representing the initial inoculation-zone diameter. Thus, 


$$
\operatorname{Lag}(h)=(D 0-Y 0) K D
$$

where: $D 0=$ diameter of the inoculation zone, $Y 0=$ intersection of the regression line with the ordinate and $K D$ = slope of the regression line (i.e., growth rate; [15] [21]).

\subsection{Evaluation of the Fungistatic and/or Fungicidal Effect of KFWP CFS}

From the plates of the growth-inhibition experiment where no fungal development occurred, the agar in the central inoculation zone was cut out and placed in $80-\mathrm{mm}$ plates containing unsupplemented BM in order to assess whether the inhibitory effect on fungal development had been fungicidal or simply fungistatic. The plates were then incubated for 30 days at $30^{\circ} \mathrm{C}$ to investigate the fungal-growth capability upon removal from the source of inhibition. This determination was carried out after 7, 15 and 30 days of incubation.

\subsection{Effect of KFWP CFS Preparations on the Fungal Germination}

We conducted assays on the inhibition of conidial germination in the presence of KFWP CFS preparations and unfermented cell-free whey supernatants after the dilution and $\mathrm{pH}$ adjustment of those fractions. A volume of 10 $\mu \mathrm{L}$ of a suspension $5 \times 10^{5}$ conidia/mL of each fungal isolate was added to a volume of $190 \mu \mathrm{L}$ of each treatment in a 96-well enzyme-linked-immunosorbent-assay (ELISA) plate (Cellstar, Frickenhausen, Germany). Treatments were performed as follows: KFWP CFS (24 h of fermentation and pH 3.7), unfermented WP acidified with lactic and acetic acid mixture (at the same concentrations measured in the KFWP CFS) and adjusted $\mathrm{pH}$ at 3.7 or unfermented WP acidified with $\mathrm{HCl}$ and adjusted $\mathrm{pH}$ at 3.7. Controls were performed with cell-free supernatant of WP added with the same concentration of conidia as used with the experimental samples. The plates were incubated for $48 \mathrm{~h}$ at $30^{\circ} \mathrm{C}$ and the optical density (OD) at $580 \mathrm{~nm}$ in the wells was monitored with a Synergy HT ${ }^{\mathrm{TM}}$ ELISA reader from Biotek Instruments (Winooski, USA). The percent inhibition was calculated by:

$$
\text { \%Inhibition }=100(\mathrm{OD} \text { control }-\mathrm{OD} \text { treated }) / \mathrm{OD} \text { control }
$$

The extent of inhibition obtained was scored semiquantitatively according to Gerez et al. [7], where inhibitions of $20 \%$ or greater were considered positive, $<40 \%$ low, $\geq 40 \%$ but $<70 \%$ moderate, and $\geq 70 \%$ high. Each determination was made in quintuplicate. Three independent assays were performed. Differences were statistically tested using one-way analysis of variance (ANOVA) and the Tukey test to determine significant differences $(\alpha=0.05)$.

\subsection{High-Performance-Liquid-Chromatography Analysis of Lactic and Acetic Acids in KFWP and KFM CFS}

The concentrations of lactic and acetic acids in the KFWP and KFM CFS were measured by high-performance liquid chromatography (HPLC) in a chromatograph (Agilent Technologies, series 1200, Santa Clara, CA, USA) with an Aminex HPX-87H ion-exchange column (Bio-Rad, Hercules, CA, USA), a mobile phase of $45 \mathrm{mM}$ $\mathrm{H}_{2} \mathrm{SO}_{4}$ (Merck, Darmstadt, Germany), a flow rate of $0.6 \mathrm{~mL} / \mathrm{min}$, and an ultraviolet detector measuring at 214 nm [16].

Pure acetic acid (Merck, Darmstadt, Germany) at concentrations of 0.42, 0.83, 1.67, 3.33, 11.70, 25.00, and $66.10 \mathrm{mM}$ and lactic acid (Carlo Erba ${ }^{\circledR}$, Milan, Italy) at 5.55, 11.10, 44.40, 88.80, 111.00, 155.00 and 209.00 $\mathrm{mM}$ were used for the control curves.

\subsection{Calculation of the Concentrations of Undissociated Organic Acids}

The concentrations of the undissociated acids were calculated by the following equation:

$$
H A=\frac{([T A] x[H+])}{([H+]+K a)}
$$

where $[H A]$ is the undissociated acid concentration (mM). $K a$ is the equilibrium constant of lactic (pKa 3.79) or acetic acid (pKa 4.75) and [TA] is the total acid concentration (mM). 


\subsection{Preparation of Supplemented Poultry Feed}

A $200 \mathrm{~mL}$ aliquot of fermented KFWP was added to $200 \mathrm{~g}$ of poultry feed Nutrisur ${ }^{\circledR}$ BB. Then the supplemented feed was dried in a convection oven at $50^{\circ} \mathrm{C}$ until a water activity $\left(a_{w}\right)$ of $0.95 \pm 0.05$ was achieved. By the same methodology, unfermented WP to give the same concentration as the fermented product were added separately to poultry feed. Feed supplemented with water and dried by the same procedure was used as control.

The water activity $\left(a_{w}\right)$ of supplemented poultry feed was measured at $20^{\circ} \mathrm{C}$ with an AquaLab Series $3 \mathrm{TE}$ meter (AquaLab, Pullman, WA, USA). The $\mathrm{pH}$ was measured using a $\mathrm{pH} 211 \mathrm{pH}$ meter equipped with an $\mathrm{HI}$ 1330B microelectrode (Hanna Instruments, Ann Arbor, MI, USA).

\subsection{Preparation of Supplemented Bread}

Bread was prepared as described below: wholemeal flour $410 \mathrm{~g}$; commercial compressed yeast (Casla ${ }^{\circledR}$, Argentina) 35 g; brown sugar 40 g; butter (La Paulina ${ }^{\circledR}$, Santa Fe, Argentina) 80 g; salt (Dos Anclas $\AA$, Argentina) 10 g; water $200 \mathrm{~mL}$. To produce bread supplemented with KFWP or unfermented WP, water (200 mL) was totally replaced by KFWP or unfermented WP $(200 \mathrm{~mL})$.

An amount of $35 \mathrm{~g}$ commercial yeast was mixed with $20 \mathrm{~g}$ brown sugar and water (or KFWP or unfermented WP). After 15 min, the mixture was placed into an electric mixer Kenwood KM 005 (Kenwood ${ }^{\circledR}$, Hampshire, UK), which was used at medium speed. Simultaneously, remaining flour, brown sugar and water or KFWP was added together with the salt and butter. Mixing process took place during $20 \mathrm{~min}$. The resulting mass was stretched, rolled and placed in fermenter Pauna Beta 107 (Pauna ${ }^{\circledR}$, Buenos Aires, Argentina) at $30^{\circ} \mathrm{C}$ with saturated water vapor for 45 minutes for fermentation. Mass was baked in an oven (Ariston ${ }^{\circledR}$, Argentina) preheated to $210^{\circ} \mathrm{C}$ for 27 minutes. The resulting bread was cooled at $25^{\circ} \mathrm{C}$ for $2 \mathrm{~h}$. Bread was cut and slices were used to perform fungal contamination assays and sensory analysis.

\subsection{Determination of the Resistance to Artificial Fungal Contamination of Bread Loaf Prepared with Kefir-Fermented Milk}

A fungal suspension (of A. flavus AFUNL5, A. parasiticus NRRL 2999 or P. sumatrense CMUNLP3) of $10^{4}$ conidia/mL was prepared. Then, $1 \mathrm{~mL}$ of this suspension was pulverized per $100 \mathrm{~g}$ bread, whereas the uncontaminated bread control was treated in the same way but with sterile distilled water. The samples were then left to dry before storage at $14^{\circ} \mathrm{C}$ in sealed polyethylene bags. Thereafter the bags were inspected daily for determination of visible signs of the fungal presence [7]. The intervening time was considered the bread resistance to the fungal contamination.

\subsection{Sensory Analysis}

In order to study the effect of the KFWP on the sensory characteristics of bread, two different techniques were performed [22].

\subsubsection{Similarity Test}

Each triangle test set consisted of 3 samples (2 identical samples and 1 different sample) placed on a tray, and the panelists were asked to identify the different sample. The panelists were asked to taste the samples in the order indicated on their ballot sheets [23]. The values obtained were analyzed using the following equation.

$$
L S \%=\left[(1.5 x(x / n)-0.5)+1.5 x Z_{\beta} x \sqrt{\left(\left(n \cdot x-x^{2}\right) / n^{3}\right)}\right] \times 100
$$

where LS\% = upper limit of the panelist's percentage; $x=$ number of correct answers; $n=$ number of panelists; $Z_{\beta}=1.64$ (value corresponding to one tail of the normal curve), $\beta=5 \%$. Statistical parameters for similarity were $\alpha=0.10 ; \beta=0.05$ with an estimated proportion of discriminators (Pd) of $30 \%$ [24].

\subsubsection{Acceptability Test}

This analysis was made by using the 9-point hedonic scale, where the panelists qualified the product with a score between 1 (“dislike very much”) to 9 (“I like very much”) [25]. 


\subsection{Statistical Analysis}

All the growth parameters were analyzed by the SIGMAPLOT $10.0^{\circledR}$ software. The results of three independent assays are presented as the mean values \pm standard deviation (SD). Differences in growth kinetics were tested for significance by the analysis of variance (ANOVA) to determine significant effects at $\mathrm{p}<0.05$ by means of the STATGRAPHICS Plus 5.1® software. All the experiments were performed at least in triplicate.

\section{Results}

\section{Characterization of Kefir Grains Grown in Milk and WP}

The standardization of kefir grain fermentation in WP was carried out with three types of kefir grains CIDCA AGK1: kefir grains grown in milk (KFM), kefir grains grown in WP during four weeks (WP-4) and twelve weeks (WP-12). Kefir grains grown in milk and those adapted to WP were able to ferment WP (Figure 1). When kefir grains WP-12 were grown in WP the acidification ability decreased in comparison with grains WP-4 (Figure 1(a)). However, kefir grains grown in milk and grains WP-4 reached a similar pH after $24 \mathrm{~h}$ fermentation (around $\mathrm{pH}$ 3.7), in contrast to WP-12 (pH 4.51) (Figure 1(a)). On the other hand, kefir grains adapted to WP decreased their biomass. Kefir grains WP-12 showed a higher decrease than WP-4, whereas kefir grains grown in milk increased their biomass (Figure 1(b)). However, the counts of LAB and yeasts remained unchanged in all three conditions.

Fermentation products of kefir grains grown in milk (KFM) and kefir grains WP-4 and WP-12 grown in WP were obtained, centrifuged, sterilized by filtration and used in the fungal-inhibition assays. KFWP CFS-4 (cell-free supernatants from WP fermented with WP-4) showed fungicidal activity, whereas KFWP CFS-12 (cell-free supernatants from WP fermented with WP-12) showed poor antifungal activity (Table 1).

Moreover, the KFWP CFS presented a change in the concentration of undissociated acids (lactic plus acetic acids). KFWP CFS-12 showed lower concentration of undissociated acids than KFWP CFS-4. KFWP CFS-4 with fungicidal activity (70\% v/v CFS in the medium) showed a concentration of undissociated acids similar to that observed in kefir fermented milk cell-free supernatants (KFM CFS) added at the same concentration (70\% $\mathrm{v} / \mathrm{v}$ CFS) in the medium. KFM CFS showed no-fungicidal activity. KFM CFS showed a lower antifungal activity, which could be due to the presence of milk compounds that produce a protective effect on the fungus. Also, the presence of WP or the decrease of the $\mathrm{pH}$ (for the addition of strong acid) per se caused no-antifungal activity (Table 1). These results suggest that kefir grains lose their fermentative and antifungal activity when they were grown in WP during long-term periods, even though the counts of LAB and yeasts were similar to both kefir grains grown in WP during four and twelve weeks.

To improve the knowledge about antifungal activity of kefir, KFWP CFS-4 was used for germination inhibition assays. CFS of WP acidified with lactic and acetic acids (at the same concentration found in KFWP CFS-4) and CFS of WP acidified with $\mathrm{HCl}$ were also assayed. Two behaviors were observed. $P$. sumatrense CMUNLP3, $P$. crustosum CMUNLP4 and F. graminearum Fg44 showed a higher sensitivity due that these fungi presented a similar inhibition for KFWP CFS, WP acidified with organic acids and WP acidified with HCl. In contrast, $A$. parasiticus NRRL2999, A. parasiticus CMUNLP7, A. flavus AFUNL5, A. terreus CMUNLP1, A. fumigatus CMUNLP2, T. longibrachiatum CMUNLP5 and Rh. microspores var. rhizopodiformis CMUNLP6 showed a lower sensitivity due to they were inhibited by KFWP CFS, whereas inhibition decreased with WP acidified with organic acids or WP acidified with $\mathrm{HCl}$ (Figure 2). These findings suggest that the antifungal activity of KFWP is produced, partially, for the presence of lactic and acetic acids plus the presence of other metabolites produced by kefir microorganisms.

Poultry feed was added with KFWP (containing total kefir microorganisms) and then artificially contaminated with several fungi. Table 2 shows that poultry feed added with KFWP showed a significant increase of the time lapsed until appearing visible fungal contamination (>30 days) for all fungi analyzed, whereas poultry feed control and poultry feed added with unfermented WP showed lower time for the visible fungal contamination (between 12 and 14 days).

Due to the promising results found, KFWP (containing total kefir microorganisms) was used as a component to produce whole-meal bread, which was artificially contaminated with several fungi. Both controls (Bread Control and Bread added with unfermented WP) showed not significant differences in the time lapsed until appearing visible fungal contamination. Bread loaves added with KFWP showed a significant increase of the time 


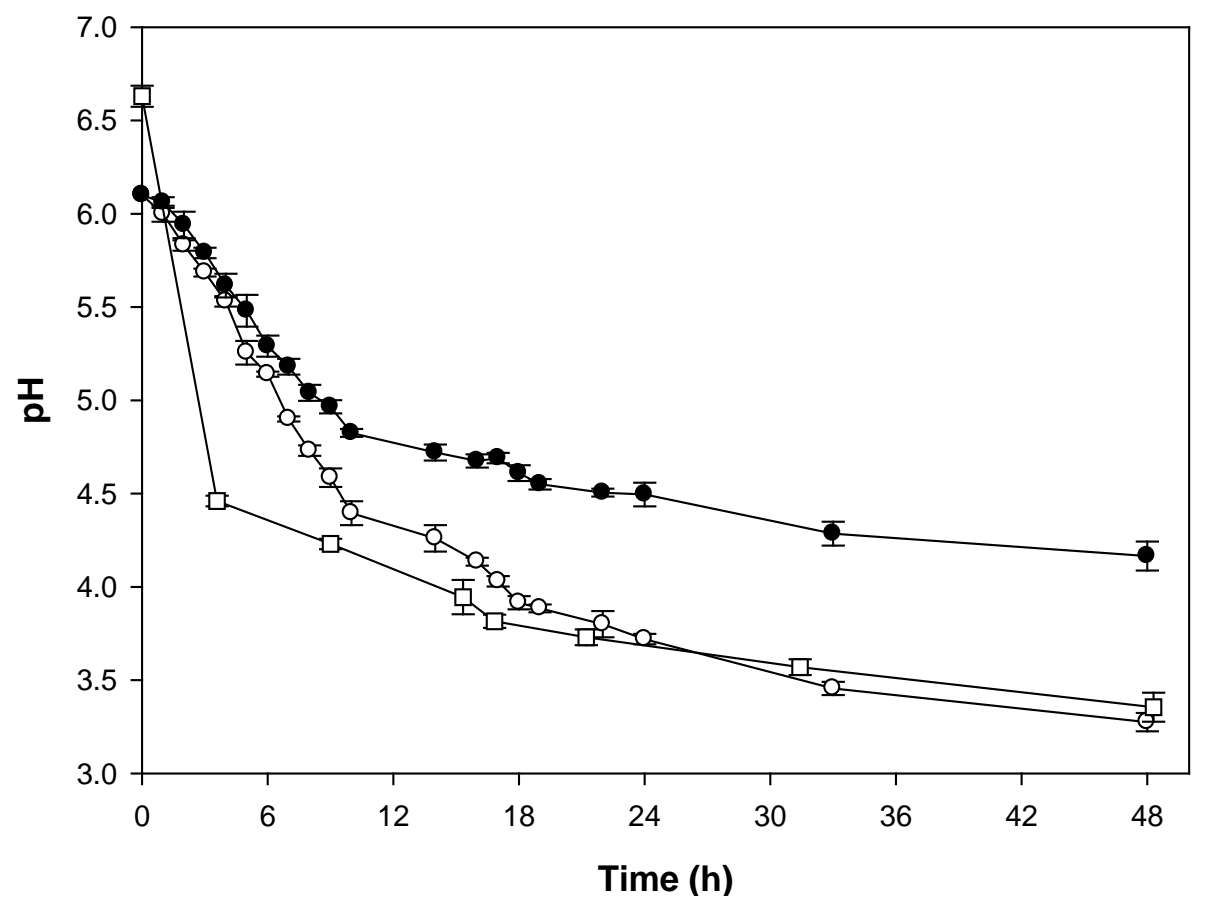

(a)

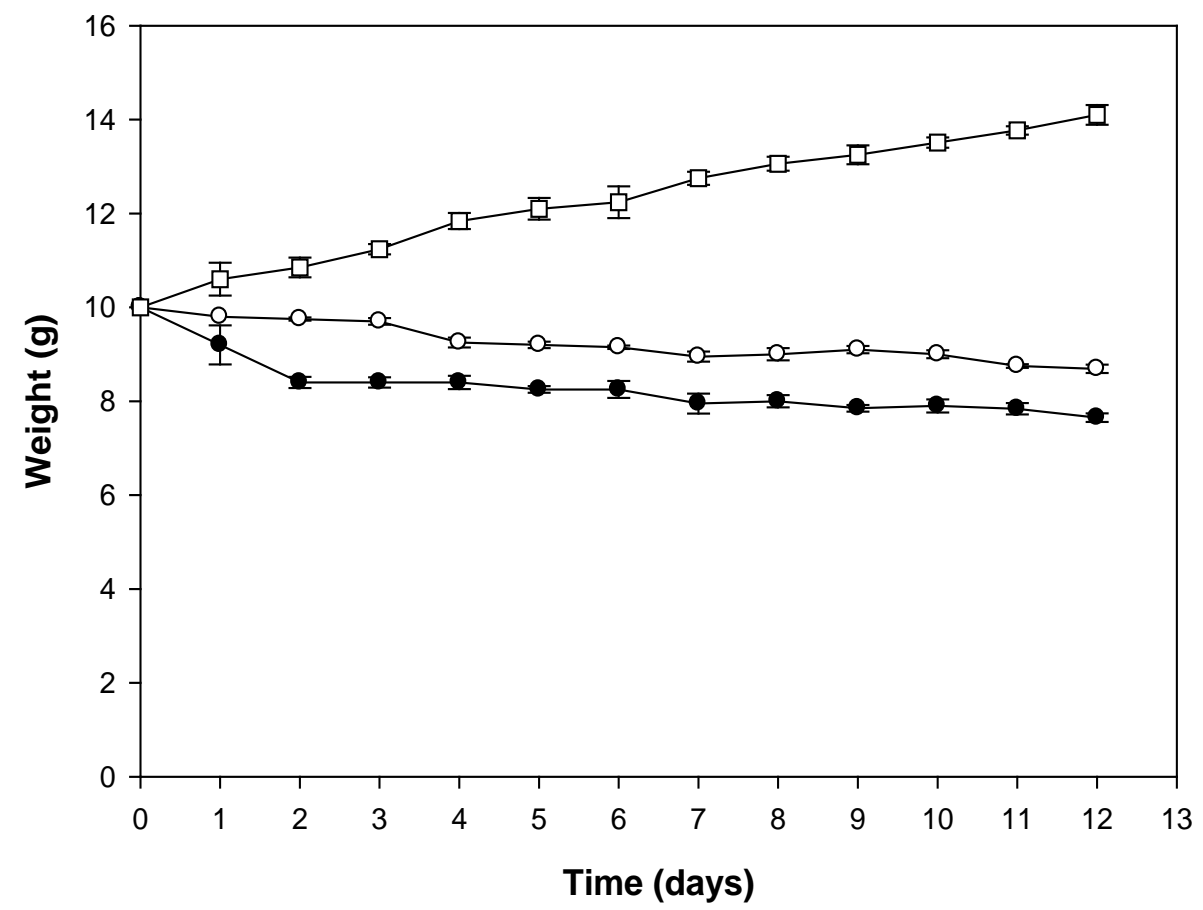

(b)

Figure 1. Acidification kinetic (a) and biomass change (b) of kefir grains CIDCA AGK1 adapted to WP during different periods of time (०) 4 weeks and (•) 12 weeks) or grown in ( $\square$ ) milk. After adaptation, $10 \mathrm{~g}$ of grains were inoculated in $100 \mathrm{ml}$ of WP and assayed for acidification kinetic. Counts of LAB and yeasts after $48 \mathrm{~h}$ in milk: $2.84 \pm 0.35 \times 10^{8} \mathrm{CFU} / \mathrm{mL}$ and $1.15 \pm 0.51 \times 10^{7} \mathrm{CFU} / \mathrm{mL}$, respectively. Counts of LAB and yeasts after $48 \mathrm{~h}$ in WP with grains WP-4: $1.08 \pm 0.14 \times 10^{8} \mathrm{CFU} / \mathrm{mL}$ and $2.24 \pm 0.38 \times 10^{7} \mathrm{CFU} / \mathrm{mL}$, respectively. Counts of LAB and yeasts after $48 \mathrm{~h}$ in WP with grains WP-12: $1.66 \pm 0.45 \times 10^{8} \mathrm{CFU} / \mathrm{mL}$ and $3.52 \pm 0.20 \times 10^{7} \mathrm{CFU} / \mathrm{mL}$, respectively. 
Table 1. $\mathrm{K}_{\mathrm{D}}$ and Lag phase of A. paraciticus NRRL2999 challenged against KFWP CFS obtained from kefir grains in WP for 4 weeks and 12 weeks and KFM CFS.

\begin{tabular}{|c|c|c|c|c|c|c|c|c|c|}
\hline \multirow[b]{2}{*}{ Treatment } & \multicolumn{3}{|c|}{ Assays with KFWP CFS-4 } & \multicolumn{3}{|c|}{ Assays with KFWP CFS-12 } & \multicolumn{3}{|c|}{ Assays with KFM CFS } \\
\hline & $\underset{(\mathbf{m m} / \mathbf{h})}{\mathbf{K}_{\mathrm{D}}}$ & $\begin{array}{l}\text { Lag phase } \\
\text { (h) }\end{array}$ & $\begin{array}{l}\text { Undissociated } \\
\text { acids (mM) }\end{array}$ & $\underset{(\mathbf{m m} / \mathbf{h})}{\mathrm{K}_{\mathrm{D}}}$ & $\begin{array}{l}\text { Lag phase } \\
\text { (h) }\end{array}$ & $\begin{array}{l}\text { Undissociated } \\
\text { acids (mM) }\end{array}$ & $\underset{(\mathbf{m m} / \mathbf{h})}{\mathbf{K}_{\mathrm{D}}}$ & $\begin{array}{l}\text { Lag phase } \\
\text { (h) }\end{array}$ & $\begin{array}{l}\text { Undissociated } \\
\text { acids (mM) }\end{array}$ \\
\hline $\begin{array}{c}\mathrm{BM}^{*} \text { plus } \\
\text { unfermented } \\
\text { WP or milk }\end{array}$ & $0.82 \pm 0.02$ & $18.3 \pm 1.2$ & 0.40 & $0.83 \pm 0.01$ & $15.2 \pm 2.4$ & 0.40 & $0.80 \pm 0.02$ & $18.1 \pm 1.7$ & 0.12 \\
\hline $\begin{array}{c}\text { BM plus } \\
\text { unfermented } \\
\text { WP or milk } \\
\text { acidified with HCl }\end{array}$ & $0.81 \pm 0.01$ & $19.5 \pm 2.5$ & 0.71 & $0.77 \pm 0.03$ & $16.5 \pm 0.5$ & 0.71 & $0.69 \pm 0.02$ & $11.9 \pm 2.2$ & 2.41 \\
\hline $\begin{array}{c}\text { BM plus KFWP } \\
\text { CFS } 25 \% \mathrm{v} / \mathrm{v}\end{array}$ & $0.68 \pm 0.02$ & $17.5 \pm 1.1$ & 6.05 & $0.75 \pm 0.03$ & $19.2 \pm 1.7$ & 1.82 & $0.58 \pm 0.03$ & $21.48 \pm 1.7$ & 8.38 \\
\hline $\begin{array}{c}\text { BM plus KFWP } \\
\text { CFS } 50 \% \mathrm{v} / \mathrm{v}\end{array}$ & $0.69 \pm 0.01$ & $33.2 \pm 2.1$ & 16.47 & $0.73 \pm 0.02$ & $22.3 \pm 0.8$ & 8.73 & $0.52 \pm 0.02$ & $25.61 \pm 1.2$ & 14.13 \\
\hline $\begin{array}{c}\text { BM plus KFWP } \\
\text { CFS } 70 \% \mathrm{v} / \mathrm{v}\end{array}$ & 0 & $>720.0$ & 34.09 & $0.62 \pm 0.02$ & $34.8 \pm 1.7$ & 19.76 & $0.40 \pm 0.01$ & $48.01 \pm 2.54$ & 32.60 \\
\hline
\end{tabular}

*BM: basal medium.

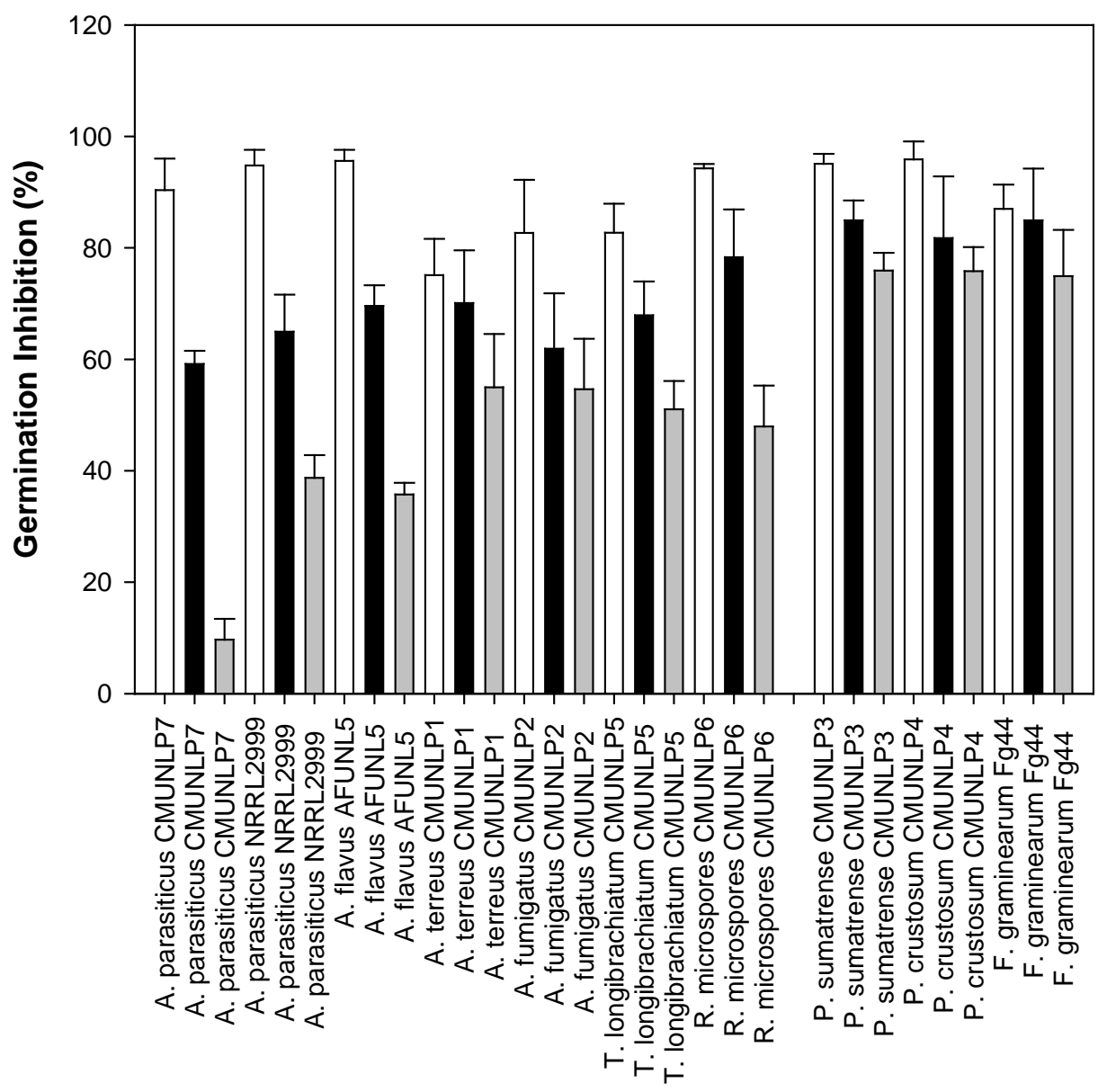

\section{Fungal strains}

Figure 2. Percentage of inhibition of conidial germination of different fungi challenged against KFWP CFS (white bars), CFS of WP acidified with organic acids (black bars) and CFS of WP acidified with HCl (gray bars). KFWP CFS were obtained as described in Materials and Methods. WP was artificially acidified with lactic plus acetic acids at the same concentrations detected in KFWP CFS. 
lapsed until appearing visible fungal contamination related to the controls for the three fungi analyzed (Table 3).

In order to determine whether bread added with KFWP could be accepted by the consumers, sensory tests were carried out. Triangle tests showed that panelists could differentiate between bread loaves elaborated with WP (unfermented WP or KFWP added to the recipe) and bread loaves control elaborated without WP (Table 4). Additionally, acceptability tests were carried out. Bread loaves added with KFWP showed a good acceptance (7.3 out of 10 points). Moreover, a value of $71.3 \%$ panelists answered that they would buy the product (Table 4). These results suggest that the application of KFWP in bread could be used to improve the resistance to fungal contamination and that a good percentage of the consumers would buy bread added with KFWP.

\section{Discussion}

Kefir grains are a complex community constituted by LAB, yeasts and acetic-acid bacteria. Milk fermented by kefir grains has been reported to contain, in general, lactic and acetic acids, acetaldehyde, ethanol, carbon dioxide (in equilibrium with carbonic acid), B vitamins, and hydrocarbons such as diacetyl [17] [26]. In our experiments, we reported that kefir grains fermented WP, as reported previously [5] [6]. However, we reported for first time the effect of the WP on the kinetic parameters of kefir grains. We demonstrated that WP as a culture medium during long-term periods caused a decrease on the fermentative ability and the biomass production (Figure 1). When kefir grains CIDCA AGK1 were grown in milk, they increased their biomass. Similar results were obtained by Guzel-Seydim et al. [27], with kefir grains grown in nonfat reconstituted milk.

Table 2. Poultry feed added with KFWP or unfermented WP and contaminated artificially with different fungus strains.

\begin{tabular}{|c|c|c|c|c|}
\hline \multirow[b]{2}{*}{ Treatment } & \multirow{2}{*}{$a_{w}$ of feed ${ }^{1}$} & \multicolumn{3}{|c|}{ Time lapsed until appearing visible fungal contamination (days) } \\
\hline & & $\begin{array}{l}\text { A. flavus } \\
\text { AFUNL5 }\end{array}$ & $\begin{array}{l}\text { A. parasiticus } \\
\text { NRRL } 2999\end{array}$ & $\begin{array}{l}\text { P. sumatrense } \\
\text { CMUNLP3 }\end{array}$ \\
\hline Control & 0.948 & $13.0 \pm 1.3$ & $14.0 \pm 0.9$ & $12.0 \pm 0.5$ \\
\hline Poultry feed added with unfermented WP & 0.953 & $13.0 \pm 0.8$ & $14.0 \pm 0.5$ & $13.0 \pm 0.5$ \\
\hline Poultry feed added with KFWP & 0.957 & $>30.0^{*}$ & $>30.0^{*}$ & $>30.0^{*}$ \\
\hline
\end{tabular}

${ }^{1} \mathrm{a}_{\mathrm{w}}$ was measured by an AquaLab Series 3 TE meter (AquaLab, Pullman, WA, USA). ${ }^{2}$ Poultry feed was inoculated with $10^{4}$ conidia/mL per each 100 $\mathrm{g}$ of feed. ${ }^{*}$ Statistical differences between the values of each column. Two independent assays were carried out.

Table 3. Bread loaves added with KFWP or unfermented WP and contaminated artificially with different fungus strains.

\begin{tabular}{ccccc} 
& & \multicolumn{2}{c}{ Time lapsed until appearing visible fungal contamination (days) } \\
\cline { 3 - 5 } Treatment & $\mathrm{a}_{\mathrm{w}}$ of bread & \\
\cline { 3 - 5 } & & $\begin{array}{c}\text { A. flavus } \\
\text { AFUNL5 }\end{array}$ & $\begin{array}{c}\text { A. parasiticus } \\
\text { NRRL 2999 }\end{array}$ & $\begin{array}{c}\text { P. sumatrense } \\
\text { CMUNLP3 }\end{array}$ \\
Bread Control & 0.943 & $5.0 \pm 0$ & $5.0 \pm 0$ & $5.0 \pm 0$ \\
Bread added with unfermented WP & 0.941 & $6.7 \pm 2.1$ & $6.3 \pm 2.3$ & $6.0 \pm 0$ \\
Bread added with KFWP & 0.947 & $12.7 \pm 1.5^{*}$ & $17.0 \pm 3.6^{*}$ & $14.3 \pm 2.5^{*}$ \\
\hline
\end{tabular}

${ }^{1} \mathrm{a}_{\mathrm{w}}$ was measured by an AquaLab Series 3 TE meter (AquaLab, Pullman, WA, USA). ${ }^{2}$ All bread loaves were inoculated to $10^{4}$ conidia/mL per each $100 \mathrm{~g}$ of bread. Two independent assays were carried out. "Statistical differences between the values of each column.

Table 4. Acceptability of bread loaves added with KFWP or unfermented WP into recipe or sprayed with KFWP.

\begin{tabular}{cccc}
\hline Treatment & Triangle Test ${ }^{*}$ & Acceptability punctuation & $\begin{array}{c}\text { Percentage of consumers } \\
\text { that would buy the product }\end{array}$ \\
\hline Control Bread & A & NA & NA \\
Bread added with unfermented WP & B & $7.7 \pm 1.6$ & 82.0 \\
Bread added with KFWP & B & $7.3 \pm 1.7$ & 71.3 \\
\hline
\end{tabular}

*Treatments with the same letter were not differentiated by the panelists. NA: not analyzed. 
Previously, Rimada and Abraham [28] found that kefir grains CIDCA AGK1 are able to ferment deproteinized whey (obtained from skimmed milk) which composition was 5.34\% lactose and $0.32 \%$ protein. Other authors have demonstrated that kefir grains CIDCA AGK10 are able to ferment cheese whey, which presented a concentration $1 \%$ and $6.5 \%$ of protein and lactose, respectively [29]. In our assays, kefir grains fermented WP, which contained $0.02 \%$ and $3.32 \%$ of protein and lactose, respectively (data not shown).

We found that the counts of LAB and yeasts of KFWP-4, KFWP-12 and KFM presented no-changes. However, with this methodology we did not detect changes in the quality of the microbial community that could indicate alterations in the balance of lactobacilli species. These results suggest that there are microbial population changes which cause a decrease in acidification ability and a possible loss of the microbial population responsible for producing the kefiran (matrix which contains the kefir microorganisms) (Figure 1).

On the other hand, we showed that KFWP CFS exerts fungicidal activity against A. parasiticus NRRL2999. Our results agreed with those obtained with kefir grains grown in cheese whey and WP that also showed antifungal activity against diverse fungi [5] [6] [9]. KFWP CFS showed fungicidal activity against A. parasiticus [5] and $F$. graminearum [6]. However, we found that kefir grains decreased their antifungal activity when they were in WP during long-term periods (twelve weeks). These results suggest that it is recommended to use KFWP CFS obtained with kefir grains grown in WP during short-term periods (not more than four weeks) to obtain satisfactory antifungal effect. Additionally, KFM CFS showed lower antifungal effect and no-fungicidal activity due to, possibly, the presence of milk compounds which protect the fungus (Table 1). Similar results were obtained with kefir-fermented milk supernatants against A. flavus AFUNL5 [30]. Additionally, KFWP CFS showed higher antifungal activity than WP acidified with organic acids or WP acidified with HCl (Figure 2). These findings suggest that the antifungal activity of KFWP is owed to the presence of lactic and acetic acids plus the presence of other metabolites produced by kefir microorganisms such as other organic acids or bacteriocins. The latter ones are a wide group of compounds with potential antimicrobial activity. In this sense, bacteriocin F1 produced by Lactobacillus paracasei subsp. tolerans isolated from Tibetan kefir grains exhibited antimicrobial activity, with a strong heat and $\mathrm{pH}$ stability [31].

On the other hand, the application of KFWP to poultry feed or bread caused the improvement of resistance to fungal contamination in both substrates (Table 2 \& Table 3). Our results are in agreement with those reported by Londero et al. [9], who demonstrated that kefir-fermented whey improve the poultry feed resistance to fungal contamination. In addition, Gerez et al. [7] found that the application of a strain of commercial yeast plus four strains of Lactobacillus to bread improved the resistance to contamination from two days (control bread) to 5 days (treated bread). Additionally, the results presented here are in concordance with those reported by Gamba et al [6], who found that kefir-fermented milk added at a concentration of $10 \% \mathrm{w} / \mathrm{v}$ to corn arepas improved their shelf life and their resistance to fungal contamination.

\section{Conclusions}

The presence of KFWP CFS in high concentrations exhibited a fungicidal capability against $A$. parasiticus NRRL2999. This capability was lost when kefir grains were grown in WP during long-term periods.

Unfermented WP acidified with lactic plus acetic acid CFS showed lower antifungal activity than that caused by KFWP CFS, suggesting the presence of other metabolites produced by kefir microorganisms that improve the antifungal activity. The application of KFWP in poultry feed and bread caused an improvement of resistance to fungal contamination. Additionally, bread added to KFWP showed a good acceptance.

\section{Acknowledgements}

We thank to CONICET (Argentina), ANPCyT, (Argentina), Universidad Nacional de La Plata (Argentina) and CIDCA (Argentina) for financial or infrastructure support. Raúl Gamba is recipient of a postdoctoral fellowship from CONICET, Graciela De Antoni is a researcher of CIC-PBA. Angela León Peláez is professor at the Universidad Nacional de La Plata.

\section{Conflict of Interest}

There is no conflict of interest with other co-authors for the publication of this manuscript in this journal. All the co-authors have contributed in the preparation of the manuscript up to the submission stage. 


\section{References}

[1] Klich, M.A. and Pitt, J.I. (1988) Differentiation of Aspergillus flavus from A. parasiticus and Other Closely-Related Species. Transactions of the British Mycological Society, 91, 99-108. http://dx.doi.org/10.1016/S0007-1536(88)80010-X

[2] Pitt, J.I. and Hocking, A.D. (1997) Fungi and Food Spoilage. Blackie Academic and Professional, London. http://dx.doi.org/10.1007/978-1-4615-6391-4

[3] Seiler, D. (1988) Microbiological Problems Associated with Cereal Based Foods. Food and Science Technology Today, 2, 37-41.

[4] Cortés-Zavaleta, O., López-Malo, A., Hernández-Mendoza, A. and García, H.S. (2014) Antifungal Activity of Lactobacilli and Its Relationship with 3-Phenyllactic Acid Production. International Journal of Food Microbiology, 173, 3035. http://dx.doi.org/10.1016/j.ijfoodmicro.2013.12.016

[5] Gamba, R.R., Colo, C., Correa, M., Astoreca, A., Alconada, T., De Antoni, G. and Peláez, A.L. (2015) Antifungal Activity against Aspergillus parasiticus of Supernatants from Whey Permeates Fermented with Kefir Grains. Advances in Microbiology, 5, 479-492. http://dx.doi.org/10.4236/aim.2015.56049

[6] Gamba, R.R., De Antoni, G. and León Peláez, A. (2016) Whey Permeate Fermented with Kefir Grains Shows Antifungal Effect against Fusarium graminearum. Journal of Dairy Research, 83, 249-255. http://dx.doi.org/10.1017/S0022029916000121

[7] Gerez, C., Torino, M., Rollán, G. and Font de Valdez, G. (2009) Prevention of Bread Mould Spoilage by Using Lactic Acid Bacteria with Antifungal Properties. Food Control, 20, 144-148. http://dx.doi.org/10.1016/j.foodcont.2008.03.005

[8] Gerez, C., Torres, M., Font de Valdez, G. and Rollán, G. (2013) Control of Spoilage Fungi by Lactic Acid Bacteria. Biological Control, 64, 231-237. http://dx.doi.org/10.1016/j.biocontrol.2012.10.009

[9] Londero, A., León, A., Diosma, G., De Antoni, G., Abraham, A., and Garrote, G. (2014) Fermented whey as poultry feed additive to prevent fungal contamination. Journal of the Science of Food and Agriculture, 94, 3189-3194. http://dx.doi.org/10.1002/jsfa.6669

[10] Garrote, G.L., Abraham, A.G. and De Antoni, G.L. (2010) Microbial Interactions in Kefir: A Natural Probiotic Drink. In: Mozzi, F., Raya, R.R. and Vignolo, G.M., Eds., Biotechnology of Lactic Acid Bacteria, Wiley-Blackwell, Ames, IO, 327-340. http://dx.doi.org/10.1002/9780813820866.ch18

[11] Ismaiel, A., Ghaly, M. and El-Naggar, A. (2011) Milk Kefir: Ultrastructure, Antimicrobial Activity and Efficacy on Aflatoxin $\mathrm{B}_{1}$ Production by Aspergillus flavus. Current Microbiology, 62, 1602-1609. http://dx.doi.org/10.1007/s00284-011-9901-9

[12] USDA (2015) Dairy: World Markets and Trade. United States Department of Agriculture Foreign Agricultural Service. Approved by the World Agricultural Outlook Board/USDA Dec 2015. http://apps.fas.usda.gov/psdonline/circulars/dairy.pdf

[13] Horton, B. (1996) Wheys of Recovery. Dairy Industry International, 61, 39-40.

[14] Davidson, P.M. and Taylor, M.T. (2007) Chemical Preservatives and Natural Antimicrobial Compounds, Chapter 33. In: Doyle, M. and Beuchat, L., Eds., Food Microbiology: Fundamentals and Frontiers, ASM Press, Washington DC, 713-745. http://dx.doi.org/10.1128/9781555815912.ch33

[15] Molina, M. and Giannuzzi, L. (1999) Combined Effect of Temperature and Propionic Acid Concentration on the Growth of Aspergillus parasiticus. Food Research International, 32, 677-682. http://dx.doi.org/10.1016/S0963-9969(99)00146-5

[16] León, A., Quintero, E., Serna, A., Gamba, R., De Antoni, G. and Giannuzzi, L. (2012) Inhibitory Activity of Lactic and Acetic Acid on Aspergillus flavus Growth for Food Preservation. Food Control, 24, 177-183. http://dx.doi.org/10.1016/j.foodcont.2011.09.024

[17] Garrote, G.L., Abraham, A.G., and De Antoni, G.L. (2000) Inhibitory Power of Kefir: The Role of Organic Acids. Journal of Food Protection, 63, 364-369.

[18] Garrote, G.L., Abraham, A.G. and De Antoni, G.L. (2001) Chemical and Microbiological Characterisation of Kefir Grains. Journal of Dairy Research, 68, 639-652. http://dx.doi.org/10.1017/S0022029901005210

[19] López-Malo, A., Barreto-Valdivieso, J., Palou, E. and San Martín, F. (2007) Aspergillus flavus Growth Response to Cinnamon Extract and Sodium Benzoate Mixtures. Food Control, 18, 1358-1362. http://dx.doi.org/10.1016/j.foodcont.2006.04.010

[20] Horner, K. and Anagnostopoulos, G. (1973) Combined Effects of Water Activity, pH and Temperature on the Growth and Spoilage Potential of Fungi. Journal of Applied Bacteriology, 36, 427-436.

http://dx.doi.org/10.1111/j.1365-2672.1973.tb04124.x 
[21] Cuppers, H., Oomes, S. and Brulm, S. (1999) A Model for the Combined Effects of Temperature and Salt Concentration on Growth Rate of Food Spoilage Molds. Applied and Environmental Microbiology, 63, 3764-3769.

[22] Lawless, H. and Heymann, H. (2010) Sensory Evaluation of Food, Principles and Practices. 2nd Edition, Springer, New York. http://dx.doi.org/10.1007/978-1-4419-6488-5

[23] Johnson, S., Duncan, S., Bianchi, L., Chang, H., Eigel, W. and O’Keefe, S. (2015) Packaging Modifications for Protecting Flavor of Extended-Shelf-Life Milk from Light. Journal of Dairy Science, 98, 1-10. http://dx.doi.org/10.3168/jds.2014-8857

[24] Hough, G. (2006) Workshop on Sensory Evaluation of Food. CIDCA (Centro de Investigación y Desarrollo en Criotecnología de los Alimentos). 9-11 October, La Plata, Argentina, p. 108.

[25] Stone, H., Bleibaum, R. and Thomas, H. (2012) Sensory Evaluation Practices. 4th Edition, Food Science and Technology, International Series, London.

[26] Toba, T. (1987) Fermented Milks Produced with Mesophilic Lactic Acid Bacteria. Kefir and Scandinavian Ropy Sour Milk. Japanese Journal of Dairy Science, 36, 235-244.

[27] Guzel-Seydim, Z., Kok-Tas, T., Ertekin-Filiz, B. and Seydim, A.C. (2011) Effect of Different Growth Conditions on Biomass Increase in Kefir Grains. Journal of Dairy Science, 94, 1239-1242. http://dx.doi.org/10.3168/jds.2010-3349

[28] Rimada, P.S. and Abraham, A.G. (2001) Polysaccharide Production by Kefir Grains during Whey Fermentation. Journal of Dairy Research, 68, 653-661. http://dx.doi.org/10.1017/S0022029901005131

[29] Londero, A., Quinta, R., Abraham, A., Sereno, R., De Antoni, G. and Garrote, G. (2011) Inhibitory Activity of Cheese Whey Fermented with Kefir Grains. Journal of Food Protection, 74, 94-100. http://dx.doi.org/10.4315/0362-028X.JFP-10-121

[30] Gamba, R.R., Caro, C.A., Martínez, O.L., Moretti, A.F., Giannuzzi, L., De Antoni, G.L. and León Peláez, A. (2016) Antifungal Effect of Kefir Fermented Milk and Shelf Life Improvement of Corn arepas. International Journal of Food Microbiology, 235, 85-92. http://dx.doi.org/10.1016/j.ijfoodmicro.2016.06.038

[31] Miao, J., Guo, H., Ou, Y, Liu, G., Fang, X., Liao, Z., Ke, Ch., Chen, Y., Zhao, L. and Cao, Y. (2014) Purification and Characterization of Bacteriocin F1, a Novel Bacteriocin Produced by Lactobacillus paracasei subsp. tolerans FX-6 from Tibetan kefir, a Traditional Fermented Milk from Tibet, China. Food Control, 42, 48-53. http://dx.doi.org/10.1016/j.foodcont.2014.01.041

\section{Submit or recommend next manuscript to SCIRP and we will provide best service for you:}

Accepting pre-submission inquiries through Email, Facebook, LinkedIn, Twitter, etc.

A wide selection of journals (inclusive of 9 subjects, more than 200 journals)

Providing 24-hour high-quality service

User-friendly online submission system

Fair and swift peer-review system

Efficient typesetting and proofreading procedure

Display of the result of downloads and visits, as well as the number of cited articles

Maximum dissemination of your research work

Submit your manuscript at: http://papersubmission.scirp.org/ 